\title{
Identification of single nucleotide polymorphisms in Toll-like receptor candidate genes associated with tuberculosis infection in water buffalo (Bubalus bubalis)
}

Flora Alfano ${ }^{1 *}$, Simone Peletto ${ }^{2}$, Maria Gabriella Lucibelli ${ }^{1}$, Giorgia Borriello ${ }^{1}$, Giovanna Urciuolo ${ }^{1}$, Maria Grazia Maniaci ${ }^{2}$, Rosanna Desiato ${ }^{2}$, Michela Tarantino ${ }^{3}$, Amalia Barone ${ }^{4}$, Paolo Pasquali ${ }^{3}$, Pier Luigi Acutis ${ }^{2}$ and Giorgio Galiero ${ }^{1}$

\begin{abstract}
Background: Toll-like receptors play a key role in innate immunity by recognizing pathogens and activating appropriate responses. Pathogens express several signal molecules (pathogen-associated molecular patterns, PAMPs) essential for survival and pathogenicity. Recognition of PAMPs triggers an array of anti-microbial immune responses through the induction of various inflammatory cytokines. The objective of this work was to perform a case-control study to characterize the distribution of polymorphisms in three candidate genes (toll-like receptor 2 , toll-like receptor 4 , toll-like receptor 9 ) and to test their role as potential risk factors for tuberculosis infection in water buffalo (Bubalus bubalis).

Results: The case-control study included 184 subjects, 59 of which resulted positive to both intradermal TB test and Mycobacterium bovis isolation (cases) and 125 resulted negative to at least three consecutive intradermal TB tests. The statistical analysis indicated that two polymorphisms exhibited significant differences in allelic frequencies between cases and controls. Indeed, the TT genotype at TLR9 $2340 \mathrm{C}>\mathrm{T}$ locus resulted significantly associated with susceptibility to bovine tuberculosis $(P=0.030, \mathrm{OR}=3.31,95 \% \mathrm{Cl}=1.05-10.40)$. One polymorphism resulted significantly associated with resistance to the disease, and included the CC genotype, at the TLR4 $672 \mathrm{~A}>\mathrm{C}$ locus $(P=0.01, \mathrm{OR}=0.26,95 \% \mathrm{Cl}=0.08-0.80)$. Haplotype reconstruction of the $T L R 2$ gene revealed one haplotype (CTTACCAGCGGCCAGTCCC) associated with disease resistance $(P=0.04, \mathrm{OR}=0.51,95 \% \mathrm{Cl}=0.27$ 0.96), including the allelic variant associated with disease resistance.

Conclusions: The work describes novel mutations in bubaline TLR2, TLR4 and TLR9 genes and presents their association with $M$. bovis infection. These results will enhance our ability to determine the risk of developing the disease by improving the knowledge of the immune mechanisms involved in host response to mycobacterial infection, and will allow the creation of multiple layers of disease resistance in herds by selective breeding.
\end{abstract}

Keywords: Bubalus bubalis, TLRs, Genetic resistance, Case control study

\footnotetext{
* Correspondence: flora.alfano@cert.izsmportici.it

${ }^{1}$ Istituto Zooprofilattico Sperimentale del Mezzogiorno, Via Salute, 2, 80055, Portici, Italy

Full list of author information is available at the end of the article
}

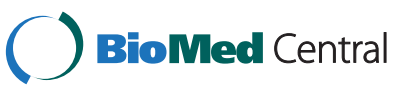

2014 Alfano et al.; licensee BioMed Central. This is an Open Access article distributed under the terms of the Creative Commons Attribution License (http://creativecommons.org/licenses/by/4.0), which permits unrestricted use, distribution, and reproduction in any medium, provided the original work is properly credited. The Creative Commons Public Domain Dedication waiver (http://creativecommons.org/publicdomain/zero/1.0/) applies to the data made available in this article, unless otherwise stated. 


\section{Background}

Tuberculosis is a major zoonosis that causes serious economic losses in livestock industry. Among domestic ruminants, an economically important role, in many parts of the world and particularly in Southern Italy, is played by water buffalo (Bubalus bubalis). Milk from this animal species is used for the production of the worldwide famous mozzarella di bufala cheese, whose product specifications allow the use of raw milk [1]. It is therefore mandatory the use of milk collected from brucellosis- and tuberculosis-free herds. Tuberculosis in Southern Italy has not yet been eradicated (prevalence of $0.7 \%$ in bovine and water buffalo herds in 2012), and there is an increase of new cases of the disease (incidence of 0.65\%) (data from the veterinary epidemiology monitoring field office, Istituto Zooprofilattico Sperimentale del Mezzogiorno www. izsmportici.it). The Italian National plan for tuberculosis control is based on a test-and-slaughter approach and does not allow vaccination. The genetic variation within the host may play a crucial role in the immunity to infections and resistance or susceptibility to disease, and selective breeding for disease-resistant genotypes might represent an emerging approach supporting disease control $[2,3]$. The role of genes in protection against bacterial infections also shown in water buffalo [4] prompted the search for polymorphisms conferring resistance to mycobacterial infection in this species.

Microbial infection initiates complex interactions between the pathogen and the host. Pathogens express several molecules, known as pathogen-associated molecular patterns (PAMPs), which are essential for survival and pathogenicity. Recognition of PAMPs triggers an array of anti-microbial immune responses through the induction of various inflammatory cytokines [5].

Toll-like receptors (TLRs) are reported to be involved in immune responses [6-8] and their polymorphisms have been associated with mutated susceptibility to mycobacteria, the causative agent of bovine tuberculosis, both in humans and different animal species [9-15]. TLRs are transmembrane proteins that play a key role in innate immunity by recognizing pathogens and subsequently activating appropriate responses. They are characterized by an extracellular N-terminal domain constituted by 16 to 28 leucine rich repeats (LRR) involved in ligand recognition [16], and an intracellular C-terminal domain known as the toll/IL-1 receptor (TIR) domain, required for the interaction and recruitment of various adaptor molecules to activate the downstream signalling pathways [17]. In water buffalo, each cell contains 25 chromosome pairs (Bubalus bubalis $2 \mathrm{n}=50$ ) [18], and the TLRs 2 and 9 loci are localized on chromosomes 17 and 21, respectively, while the TLR 4 locus is located on chromosome 3 [19].

Toll-like receptors 2 and 4 mediate their effects by recognizing bacteria, including mycobacteria. Toll-like receptor 2 is sensitive to peptidoglycan and to lipoarabinomannan. Toll-like receptor 4 is involved in bacterial lipopolysaccharide recognition [20], but its sensitivity to mycobacterial antigens has also been reported [21]. Toll-like receptor 9 is essential for responses to bacterial DNA and in particular to unmethylated $\mathrm{CpG}$ dinucleotides (CpG DNA) [22].

The aim of this study was (i) to identify single nucleotide polymorphisms (SNPs) in the coding sequence (CDS) of three candidate genes: toll-like receptor 2 (TLR 2), toll-like receptor 4 (TLR 4), toll-like receptor 9 (TLR 9), (ii) to characterize the distribution of the detected polymorphisms and (iii) to perform a case-control study to test their role as potential risk factors for tuberculosis infection in water buffalo.

\section{Results}

Identification of SNPs

The water buffalo TLR2 and TLR9 genes consist of two exons, while the TLR4 consists of three exons. The analysis of the entire CDSs enabled us to identify 29 new SNPs. Specifically, 18 were identified in TLR2 (five nonsynonymous and 13 synonymous), nine in TLR4 (five non-synonymous and four synonymous), and two in TLR9 (both synonymous). All the found SNPs were bi-allelic with the exception of a tri-allelic SNP (572 A > CG) found in TLR4. In addition we identified a dinucleotidic SNP (482/483 GC > CT) in TLR2. Table 1 shows all the SNPs, their positions in the CDS, the encoded protein codon and the GenBank reference number.

\section{Case-control study}

Calculation of the allelic and genotypic frequencies, and application of the $\chi^{2}$ test, revealed that both populations (cases and controls) conformed to the Hardy-Weinberg equilibrium with regard to all the polymorphic loci $(P>0.05)$ of the TLRs 2, 4 and 9 genes.

As a first step of the genetic association study, Pearson s chi-squared test was carried out for each SNP both independently and as genotype. As many SNPs exhibited a strong linkage disequilibrium a multiple testing correction was applied by permutation analysis. Within the 29 analysed polymorphic sites, three SNPs exhibited statistically significant differences in frequency distribution of one or more associated genotypes between cases and controls (Table 2). In particular, one SNP was located in the TLR2 gene (1650 G>A ), one SNP in TLR4 $(672 \mathrm{~A}>\mathrm{C})$ and one in TLR9 $(2340 \mathrm{C}>\mathrm{T})$. Then, in order to test inheritance model, a deviation test from additivity was performed with plink version 1.07, suggesting in our case an additive model of inheritance. SNPs significantly associated to the disease $(P<0.05)$ were used for further analysis: a logistic regression model was performed to 
Table 1 Detected SNPs in bubaline TLRs2, 4 and 9 genes

\begin{tabular}{|c|c|c|c|c|}
\hline Gene & $\mathrm{SNP}^{a}$ & $A A$ change $^{b}$ & Protein domain $^{c}$ & dbSNP ID \\
\hline \multirow[t]{18}{*}{ TLR2 } & $42 C>T$ & Silent 14 & $-^{d}$ & rs1388116474:C > T \\
\hline & $53 \mathrm{C}>\mathrm{T}$ & M18T & - & rs1388116475:C > T \\
\hline & $108 \mathrm{C}>\mathrm{T}$ & Silent 36 & LRR 8 & rs1388116476:C > T \\
\hline & $153 \mathrm{G}>\mathrm{A}$ & Silent 51 & LRR_RI & rs1388116477:G > A \\
\hline & $156 C>T$ & Silent 52 & LRR_RI & rs1388116478:C > T \\
\hline & $374 \mathrm{~T}>\mathrm{C}$ & $\mathrm{A} 125 \mathrm{~V}$ & LRR 8 & rs1388116479:T > C \\
\hline & $381 A>G$ & Silent 127 & LRR 8 & rs1388116480:A > G \\
\hline & $482 / 483 \mathrm{GC}>\mathrm{CT}$ & $\mathrm{S} 161 \mathrm{~T}$ & LRR 8 & rs1388116481:GC > CT \\
\hline & $519 G>C$ & Silent 173 & LRR_RI & rs1388116482:G >C \\
\hline & $1034 A>G$ & S345N & - & rs1388116483:A > G \\
\hline & $1375 \mathrm{~T}>\mathrm{C}$ & Silent 459 & LRR4 & rs1388116484:T > C \\
\hline & $1407 C>T$ & Silent 469 & LRR4 & rs1388116485:C > T \\
\hline & $1650 \mathrm{G}>\mathrm{A}$ & Silent 550 & LRR_CT & rs1388116486:G > A \\
\hline & $1678 A>G$ & A560T & LRR_CT & rs1388116487:A > G \\
\hline & $1707 \mathrm{C}>\mathrm{T}^{e}$ & Silent 569 & LRR_CT & rs1388116488:C > T \\
\hline & $1731 \mathrm{C}>\mathrm{T}$ & Silent 577 & LRR_CT & rs1388116489:C > T \\
\hline & $1740 \mathrm{C}>\mathrm{T}$ & Silent 580 & LRR_CT & rs1388116490:C > T \\
\hline & $2064 T>C$ & Silent 688 & $\mathrm{TIR}$ & rs1388116491:T>C \\
\hline \multirow[t]{10}{*}{ TLR4 } & $572 \mathrm{~A}>\mathrm{C}^{f}$ & Y191S & LRR8 & rs1388116492:A > CG \\
\hline & $572 \mathrm{~A}>\mathrm{G}^{f}$ & silent & LRR8 & rs1388116492:A > CG \\
\hline & $574 \mathrm{C}>\mathrm{T}$ & Q192W & LRR8 & rs1388116493:C > T \\
\hline & $575 A>G$ & Q192W & LRR8 & rs1388116494:A>G \\
\hline & $576 \mathrm{~T}>\mathrm{G}$ & Silent192 & LRR8 & rs1388116495:T>G \\
\hline & $577 \mathrm{G}>\mathrm{A}$ & E193K & LRR8 & rs1388116496:G > A \\
\hline & $579 A>G$ & Silent193 & LRR8 & rs1388116497:A > G \\
\hline & $647 \mathrm{G}>\mathrm{A}$ & Silent216 & LRR_RI & rs1388116498:G > A \\
\hline & $662 \mathrm{G}>\mathrm{A}$ & Silent221 & - & rs1388116499:G > A \\
\hline & $672 A>C$ & Silent224 & - & rs1388116500:A > C \\
\hline \multirow[t]{2}{*}{ TLR9 } & $2340 \mathrm{C}>\mathrm{T}$ & Silent780 & - & rs1388116501:C> T \\
\hline & $2475 A>G$ & Silent825 & - & rs1388116502:A > G \\
\hline
\end{tabular}

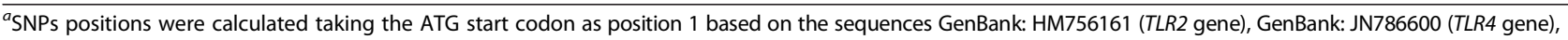
GenBank: HQ242778 (TLR9 gene).

${ }^{b}$ Amino acid positions are given according to the ATG start codon.

'Protein domain has been predicted from the cds sequence by using the Conserved Domain Database available at http://www.ncbi.nlm.nih.gov/Structure/cdd/wrpsb.cgi $[23,24]$.

${ }^{d}$ Protein position with unknown function.

${ }^{e}$ This SNP is conserved also in the bovine species [9].

${ }^{f}$ This polymorphic site exhibits a SNP with three different alleles (572 A > CG).

calculate the Odds Ratio (OR) with the wild type category used as a baseline (Table 3).

In the TLR2 gene, the $1650 \mathrm{G}>\mathrm{A}$ locus exhibited a $X^{2}$ test of independence with a significant $P$-value $(P=$ 0.018) while the OR for the AA genotype, calculated with the Woolf s method, exhibited a not statistically significant value $(P=0.0512$, OR $=0.10,95 \% \mathrm{CI}=0.01$ 1.74). However, in this case, a significant test for trend $(P=0.01)$ in calculating OR values in logistic regression indicates a plausible strong correlation with resistance to the disease.

For the TLR4 gene, the SNP $672 \mathrm{~A}>\mathrm{C}$ showed a $X^{2}$ test with a significant $P$-value $(P=0.031)$; the OR demonstrated a significant $P$-value $(P=0.012)$ for the $\mathrm{CC}$ genotype at the $672 \mathrm{~A}>\mathrm{C}$ locus and a value lower than $1(\mathrm{OR}=0.26,95 \% \mathrm{CI}=0.08$ to 0.80$)$, thus indicating a significant association with resistance to tuberculosis. 
Table 2 Results of permutation analysis

\begin{tabular}{|c|c|c|}
\hline Chromosome & SNP & Empirical $P$-value \\
\hline 17 & $42-C>T$ & 0.9000 \\
\hline 17 & $53-C>T$ & 0.1967 \\
\hline 17 & $108-C>T$ & 0.1714 \\
\hline 17 & $153-G>A$ & 0.2195 \\
\hline 17 & $156-C>T$ & 0.9452 \\
\hline 17 & 374-T>C & 0.1229 \\
\hline 17 & $381-A>G$ & 0.9788 \\
\hline 17 & 482/483-GC >CT & 0.8222 \\
\hline 17 & $519-G>C$ & 0.5175 \\
\hline 17 & $1034-A>G$ & 0.2191 \\
\hline 17 & $1375-\mathrm{T}>\mathrm{C}$ & 0.1302 \\
\hline 17 & $1407-C>T$ & 0.8738 \\
\hline 17 & $1650-G>A$ & $0.0138^{*}$ \\
\hline 17 & $1678-A>G$ & 0.1505 \\
\hline 17 & $1707-C>T$ & 0.2203 \\
\hline 17 & $1731-C>T$ & 0.9286 \\
\hline 17 & $1740-C>T$ & 0.8985 \\
\hline 17 & 2064-T>C & 0.1296 \\
\hline 3 & 572 C > A G & 0.4909 \\
\hline 3 & $574 C>T$ & 0.4288 \\
\hline 3 & $575 A>G$ & 0.4380 \\
\hline 3 & $576 \mathrm{~T}>\mathrm{G}$ & 0.2490 \\
\hline 3 & $577 \mathrm{G}>\mathrm{A}$ & 0.6373 \\
\hline 3 & $579 A>G$ & 0.2551 \\
\hline 3 & $647 \mathrm{G}>\mathrm{A}$ & 0.1735 \\
\hline 3 & $662 \mathrm{G}>\mathrm{A}$ & 0.1006 \\
\hline 3 & $672 A>C$ & $0.0183^{*}$ \\
\hline 21 & $2340 \mathrm{C}>\mathrm{T}$ & $0.0521^{*}$ \\
\hline 21 & $2475 A>G$ & 0.1254 \\
\hline
\end{tabular}

*statistically significant.

Table 3 Polymorphic sites including genotypes with statistically significant differences in frequency distribution between cases and controls

\begin{tabular}{llllll}
\hline Gene & SNPs & Genotype & $P$-value & OR & Cl 95\% \\
\hline TLR2 & $1650 \mathrm{G}>\mathrm{A}$ & $\mathrm{G} / \mathrm{A}$ & 0.166 & 0.612 & $0.26-1.01$ \\
& & $\mathrm{~A} / \mathrm{A}$ & 0.021 & 0.000 & \\
TLR4 & \multirow{2}{*}{$672 \mathrm{~A}>\mathrm{C}$} & $\mathrm{A} / \mathrm{C}$ & 0.689 & 0.865 & $0.42-1.76$ \\
& & $\mathrm{C} / \mathrm{C}$ & $\mathbf{0 . 0 1 2}$ & $\mathbf{0 . 2 5 8}$ & $\mathbf{0 . 0 8 - 0 . 8 0}$ \\
TLR9 & \multirow{2}{*}{$2340 \mathrm{C}>\mathrm{T}$} & $\mathrm{C} / \mathrm{T}$ & 0.048 & 2.917 & $0.96-8.89$ \\
& & T/T & $\mathbf{0 . 0 3 0}$ & $\mathbf{3 . 3 0 6}$ & $\mathbf{1 . 0 5 - 1 0 . 4 0}$
\end{tabular}

Bold lines highlight genotypes with statistically significant $P$-values and $\mathrm{ORs}$.
In the TLR9 gene, the analysis revealed one polymorphic site $(2340 \mathrm{C}>\mathrm{T})$ with a significant $P$-value $(0.053)$ at the $\mathrm{X}^{2}$ test including one genotype $(\mathrm{T} / \mathrm{T})$ associated with susceptibility to the disease $(P=0.030$ and $\mathrm{OR}=3.31$, 95\% CI $=1.05-10.40$ ).

Haplotype reconstruction based on TLR2 polymorphisms performed by PHASE software, generated 25 possible haplotypes, seven of which displayed a frequency greater than $0.01 \%$ in the whole sample. The software PHASE can reveal any significant imbalance in haplotype distribution between groups by performing a permutation test; the application of this analysis to the detected haplotypes revealed the presence of one haplotype (CTTACCA GCGGCCAGTCCC) associated with disease resistance $(P=0.041$ and $\mathrm{OR}=0.51,95 \% \mathrm{CI}=0.27-0.96)$. This haplotype contained the allelic variant that resulted possibly associated with resistance to the disease.

In the TLR4 gene, 34 haplotypes were observed in the two tested groups, six of which displayed a frequency greater than $0.01 \%$ in the whole population. None of the predicted haplotypes showed a significant association with resistance/susceptibility to tuberculosis.

Finally, four haplotypes were observed in the TLR9 gene, none of which displayed a significant association with resistance/susceptibility to tuberculosis.

\section{Discussion}

The polymorphisms of single nucleotides constitute excellent genetic markers for various population studies as they can, for instance, reveal traces of natural selection. Moreover, it is now known that the contribution of genes to the incidence of or predisposition to diseases can be determined by comparing inter-individual genetic differences.

Each individual, to a greater or lesser degree than others, is genetically prone to develop certain diseases. In most cases, the susceptibility or resistance to a given pathology does not of course mean that the individual will necessarily be affected by the disease or remain disease-free; it does, however, indicate a higher or lower risk than that of the general population. Indeed, the onset of symptoms is due to an interaction between genetic factors and environmental factors. Nevertheless, cases have been described in which genetic factors are sufficient to determine the course of infection. In scrapie, for instance, which is a transmissible disease of sheep and goats caused by a prion, there are reports of genotypes that are defined as resistant, which are practically refractory to natural infection $[25,26]$.

Our analysis of the water buffalo TLR2, TLR4 and TLR9 genes enabled us to identify 29 SNPs. In the three genes, the $76 \%$ of the SNPs fell within the LRR protein domains, regions responsible for ligand recognition. This finding is in agreement with conservation of the transmembrane and functional TIR domains already observed in human, bovine and murine TLRs genes [9-13]. 
The case-control study carried out revealed the presence of associations between some of the identified polymorphisms and resistance/susceptibility to the disease caused by $M$. bovis. Specifically, in TLR4, we observed a correlation between resistance to disease and the genotype $\mathrm{C} / \mathrm{C}$ at the $672 \mathrm{~A}>\mathrm{C}$ locus $(P=0.012, \mathrm{OR}=0.26,95 \% \mathrm{CI}=$ 0.08-0.80) when a logistic regression model was performed. A likewise correlation with weak statistical evidence was seen in TLR2 at the $1650 \mathrm{~A}>\mathrm{G}$ locus when a logistic regression model was performed between wild type genotype and mutated genotype $(P=0.0512$, OR $=0.10$, $95 \% \mathrm{CI}=0.01-1.74)$. Moreover, a correlation was seen between susceptibility to tuberculosis and the $\mathrm{T} / \mathrm{T}$ genotype at the $2340 \mathrm{C}>\mathrm{T}$ locus in the TLR9 gene $(P=0.030$, $\mathrm{OR}=3.31$, 95\% CI $=1.05-10.40)$.

Haplotype reconstruction based on TLR2 polymorphisms enabled us to ascertain whether the interaction of the single alleles exerted an influence on the animals response to the disease; indeed, this analysis revealed a haplotype (CTTACCAGCGGCCAGTCCC) that was associated with disease resistance $(P=0.041$ and $\mathrm{OR}=0.51$, 95\% CI $=0.27-0.96)$. This haplotype contained the allelic variant which resulted possibly associated with resistance to the disease. However, as this variant is not exclusive of the associated haplotype, we may hypothesise that other loci exert a modulatory effect.

Haplotype reconstruction and the permutation test conducted on the polymorphisms identified in TLR4 did not retrieve any disease-associated haplotype.

Previous studies have demonstrated the influence of genetic factors and some gene polymorphisms on susceptibility to several bacterial diseases, including TB. TLRs have been found to be associated with both the innate immune and adaptive immune responses, and play a crucial role in the immune recognition of $M$. tuberculosis. Mutations and polymorphisms in TLRs and TLR signalling molecules have revealed the importance of TLRs both in human and animal defence against disease [14-22,25-28]. One nsSNP in TLR2 (Arg753Gln) has been shown to increase human predisposition to staphylococcal infection, tuberculosis, rheumatic fever and urinary tract infection [10-15]. A nsSNP in the bovine TLR2 gene (Val220Met) has been shown to decrease the response to M. avium subsp. paratuberculosis (Map) [11], while another SNP in the same gene, C1903T (Silent569), was found to be associated with resistance to Map infection in cattle [9]. Several polymorphisms have been found in the bovine TLR4 gene, 12 SNPs affecting ligand binding domain [29] and four SNPs associated with susceptibility to Map infection [11]. Studies conducted on the bovine TLR9 gene demonstrated a high degree of genetic variability in this gene [14-22,25-30], even though no significant association with bovine tuberculosis could be inferred from mutations in this gene [14]. A SNP in the human TLR9 gene (rs352139) was found to be associated with susceptibility to TB $(P=0.01, \mathrm{OR}=2.37)$ [31]. In our study, among the polymorphisms identified in water buffalo, only one (C1707T in the TLR2 gene) showed correspondence to a polymorphism reported in cattle (T1903C) [9]. Specifically, Koets and coworkers [9] found this SNP associated with resistance to Map, while in water buffalo the same polymorphism did not show any significant association with susceptibility/ resistance to $\mathrm{TB}$.

To date, it is estimated that about 50 human diseases are caused entirely or partly by synonymous mutations, and it has also been demonstrated that they play a role in disease resistance [32,33]. In the human TLR2, for example, synonymous mutations have been identified which are associated with resistance to liver cell carcinoma [17]. A recent meta-analysis identified a significant association between an intron mutation of TLR9 and tuberculosis in humans [34].

Moreover, it has been observed that silent mutations can interfere with various stages of protein construction , from DNA transcription to the translation of mRNA into protein.

Silent changes in codons located in the exonic splicing enhancers (ESE) can prevent introns from being properly eliminated. A notable example of the damage that can be caused by mutations in a splicing enhancer has been documented for the CFTR (Cystic Fibrosis Transmembrane Conductance Regulator) gene [35,36].

Finally, synonymous mutations can alter the stability of the transcript by reducing its affinity for RNA binding proteins. Indeed, in humans, a synonymous mutation of the gene coding for corneodesmosine $(C D S N)$ has been associated with the onset of psoriasis in various ethnic groups [37].

An alternative hypothesis could be that some of the detected synonymous mutations are not directly related to disease susceptibility/resistance, but rather that one or more are linked to other functional mutations on the same chromosome which have not yet been identified. Functional studies will be crucial in order to understand how these polymorphisms act.

\section{Conclusions}

The work describes novel mutations in the bubaline TLR2, TLR4 and TLR9 genes and describes their association with $M$. bovis infection. Studies of the genetic factors involved in complex diseases have not yet provided clear explanations for the onset of such diseases, though they may help to identify their underlying physio-pathological pathways. A thorough knowledge of these mechanisms will improve our ability to determine the risk of developing the disease and to understand it in its entirety. This will pave the way to create multiple layers of disease resistance in herds by selective breeding and also to identify and synthesize innovative drugs. 


\section{Methods}

\section{Study design}

Genetic association between SNPs and TB was studied by a case-control approach on 184 water buffaloes from 22 herds in the Campania region. Sample collection was performed within the Italian National Plan for the control of tuberculosis, which imposes culling of all the subjects positive to the delayed hypersensitivity test [38] and microbiological processing of the lymphoid tissue for isolation of $M$. bovis [38]. Our analyses, performed during the period 2009-2011, revealed the presence of 59 animals positive to both intradermal TB test and $M$. bovis microbiological isolation. These 59 animals were therefore classified as cases for the case-control study. The choice of the microbiological test to confirm cases identification was considered in order to exclude the possibility of false-positive subjects diagnosed by the delayed hypersensitivity test. The control subjects were collected among the animals which tested negative to repeated intradermal TB tests (at least three tests) during the entire period of the study. The control animals were at least five years-old, and were born and raised in the same herds of cases to ensure an equal level of exposure to infection. The number of controls was estimated taking into account an odds ratio value of 2.0 as a threshold for significance, with a ratio for cases and controls of 1:2 (power $=80 \%$, confidence $=95 \%$ ) [12]. Based on these parameters, with an imposed number of cases (59), the required number of controls was 108 for a one-tailed analysis. The present case-control study therefore included 59 cases and 125 controls.

\section{TLRs sequencing}

DNA was extracted from blood (control animals) and lymph node (cases) samples using the QIAamp DNA mini kit (Qiagen, Hilden, Germany) according to the manufacturer s protocol. PCR primers for amplification of the CDS of the genes TLR2, TLR4 and TLR9 were designed using the Web interface Primer3; they are shown in Table 4. The TLR2 coding sequence was amplified using two primer pairs according to the following touchdown PCR protocol: initial step of 7 cycles of $1 \mathrm{~min}$ at 95C, $1 \mathrm{~min}$ at $65 \mathrm{C}$ (decreasing by $1 \mathrm{C}$ after each cycle), $1 \mathrm{~min} 30 \mathrm{~s}$ at $72 \mathrm{C}$, followed by 35 cycles of $1 \mathrm{~min}$ at $95 \mathrm{C}$,

Table 4 PCR primers, annealing temperatures and amplicon length of amplified bubaline TLRs 2, 4 and 9 genes

\begin{tabular}{|c|c|c|c|}
\hline Oligo & Sequence $\left(5^{\prime} 3^{\prime}\right)$ & PCR T ann (C) & Amplicon (bp) \\
\hline \multirow[t]{2}{*}{ TLR2 A } & For: TTGTAGGTCAAATCACTGGACA & $58^{a}$ & $1331 \mathrm{bp}$ \\
\hline & Rev: TCCTGGCCACTGACAAGTTT & & \\
\hline \multirow[t]{2}{*}{ TLR2 B } & For: GCCCTTCCTTCAAACCTTG & $58^{a}$ & $1234 \mathrm{bp}$ \\
\hline & Rev: CACCACCAGACCAAGACTGA & & \\
\hline \multirow[t]{2}{*}{ TLR4 A } & For: GTGTGGAGACCTAGATGACTGG & 60 & 706 bp \\
\hline & Rev: GTACGCTATCCGGAATTGTTCA & & \\
\hline \multirow[t]{2}{*}{ TLR4 B } & For: CTTTCCTGGAGGGACTGTGC & 60 & $435 \mathrm{bp}$ \\
\hline & Rev: CCACGAAGTTTGAACCTAAGGTAA & & \\
\hline \multirow[t]{2}{*}{ TLR4 C } & For: CTACCAAGCCTTCAGTATCTAG & 60 & $743 \mathrm{bp}$ \\
\hline & Rev: GGCATGTCCTCCATATCTAAAG & & \\
\hline \multirow[t]{2}{*}{ TLR4 D } & For: AAGGACCAGAGGCAGCTCTT & 58 & $801 \mathrm{bp}$ \\
\hline & Rev: TAACTGAACACGCCCTGCAT & & \\
\hline \multirow[t]{2}{*}{ TLR9 A } & For: CCAGCCTCTCCTTAATCTCC & 54 & 718 bp \\
\hline & Rev: CGGAACCAATCTITCTCTAGTT & & \\
\hline \multirow[t]{2}{*}{ TLR9 B } & For: CCTGACACCTTCAGTCACCT & 55 & $651 \mathrm{bp}$ \\
\hline & Rev: GCGGGTAAACATCTCTTGCT & & \\
\hline \multirow[t]{2}{*}{ TLR9 C } & For: CGTCAGCTCAAAGGACTTCA & 56 & $546 \mathrm{bp}$ \\
\hline & Rev: AGGGTGTGCAGATGGTTCTC & & \\
\hline \multirow[t]{2}{*}{ TLR9 D } & For: GGGAGACCTCTATCTCTGCTIT & 56 & $428 \mathrm{bp}$ \\
\hline & Rev: CGCTCACGTCTAGGATTTTC & & \\
\hline \multirow[t]{2}{*}{ TLR9 E } & For: CTTCAGAAGCTGGACGTGAG & 55 & $685 \mathrm{bp}$ \\
\hline & Rev: TCTTGCGGCTGCTGTAGAC & & \\
\hline \multirow[t]{2}{*}{ TLR9 F } & For: TGCTCTATGATGCCTTCGTG & 55 & $424 \mathrm{bp}$ \\
\hline & Rev: AGGTTGGCCCAGAAACTACC & & \\
\hline
\end{tabular}

${ }^{a}$ For these primer pairs a touchdown PCR thermal profile was used. 
$1 \mathrm{~min}$ at $58 \mathrm{C}, 1 \mathrm{~min} 30 \mathrm{~s}$ with a final extension of $10 \mathrm{~min}$ at $72 \mathrm{C}$. The TLR4 CDS was amplified using four primers sets with the following thermal profile: 35 cycles of $30 \mathrm{~s}$ at $95 \mathrm{C}, 30 \mathrm{~s}$ at $\mathrm{T}$ ann and $45 \mathrm{~s}$ at $72 \mathrm{C}$, with a final extension of $10 \mathrm{~min}$ at $72 \mathrm{C} . \mathrm{T}_{\text {ann }}$ is the annealing temperature specifically indicated for each primers pair in Table 4. The TLR9 CDS was amplified using six primer sets with the following thermal profile: 5 cycles of $30 \mathrm{~s}$ at $95 \mathrm{C}, 20 \mathrm{~s}$ at $60 \mathrm{C}$, and $15 \mathrm{~s}$ at $72 \mathrm{C}$ followed by 30 additional cycles of $20 \mathrm{~s}$ at $95 \mathrm{C}, 20 \mathrm{~s}$ at $\mathrm{T}_{\mathrm{ann}}$, and $30 \mathrm{~s}$ at $72 \mathrm{C}$, with a final extension of $10 \mathrm{~min}$ at $72 \mathrm{C}$. All thermal profiles included an initial step at $95 \mathrm{C}$ for $15 \mathrm{~min}$ for Taq DNA polymerase activation. PCR reactions were performed with the HotStar HiFidelity Polymerase Kit (Qiagen), and the reaction mixture included $50 \mathrm{ng}$ of genomic DNA and $0.5 \mu \mathrm{M}$ of each primer (forward and reverse) in a final volume of $25 \mu \mathrm{l}$. Amplicons were purified (QiaQuick purification kit, Qiagen), bi-directionally sequenced using the Big Dye Terminator cycle sequencing kit v.1.1 or v.3.1 (Life Technologies) and purified using the DyeEx spin kit (Qiagen). Samples $(5 \mu \mathrm{l})$ were denatured with $10 \mu \mathrm{l}$ of Hi-Di formamide (Life Technologies) at 95C for $5 \mathrm{~min}$, and separated by capillary electrophoresis on either ABI PRISM 310 or 3130 sequencers (Life Technologies). Sequencing data were manually inspected by the Sequencing Analysis software v5.4 (Life Technologies).

\section{SNP selection and genotyping}

Sequences were analyzed by multiple alignment using BioEdit v.7.1.3 [39] and SeqManII 5.00 software (DNASTAR Inc.). The 184 water buffalo sequences of the TLR2, TLR4 and TLR9 genes were compared with the publicly available sequences GenBank:HM756161 (Toll-like receptor 2 gene, complete cds), GenBank:JN786600 (Toll-like receptor 4 gene, complete cds), GenBank:HQ242778 (Toll-like receptor 9 gene, complete cds), respectively. Each forward and reverse sequence from a single DNA sample was compared with the other in order to generate a consensus sequence and to identify polymorphisms among the samples.

\section{Genetic association analysis}

Genotype frequencies were tested for deviation from Hardy-Weinberg equilibrium (HWE) by using Fisher Exact test and Chi-square test $\left(\chi^{2}\right)$. Pearson s $\chi^{2}$ test was carried out for each SNP both independently and by using a multiple testing correction based on permutation [40,41].

SNPs that were significantly associated with the disease were entered in an univariate logistic regression model. All statistical analyses were performed using Stata statistical software, release 10.0 (Stata Corp., College Station, TX, USA) and PLINK software (PLINK 1.07, Shaun Purcell http://pngu.mgh.harvard.edu/purcell/plink/).

Haplotype reconstruction was performed using PHASE software, version 2.1 [42].
Competing interests

The authors declare that they have no competing interests.

\section{Authors contributions}

FA carried out the molecular genetic studies, molecular typing assays, sequence analysis and drafted the manuscript, SP contributed to the molecular analysis and critically revised the manuscript, MGL and GB carried out molecular typing assays, contributed to interpretation of data and manuscript drafting, GU, MT and MGM carried out a part of the molecular analyses and contributed to sequence analysis, RD performed the statistical analysis, AB, PP, PLA and GG conceived the study and participated in its design and coordination, and helped to draft the manuscript. All authors read and approved the final manuscript.

\section{Acknowledgements}

We thank Cristiana Maurella, DVM MSE (BEAR Biostatistica Epidemiologia e Analisi del Rischio, Istituto Zooprofilattico Sperimentale del Piemonte, Liguria e Valle d Aosta, Turin, Italy) for helpful advices on the statistical analysis.

Funding for the project was provided by the Italian Ministry of Health (grant IZS ME 02/09 RC).

The funders had no role in study design, data collection and analysis, decision to publish, or preparation of the manuscript.

\section{Author details}

${ }^{1}$ Istituto Zooprofilattico Sperimentale del Mezzogiorno, Via Salute, 2, 80055, Portici, Italy. ${ }^{2}$ Istituto Zooprofilattico Sperimentale del Piemonte Liguria e Valle d Aosta, Via Bologna, 148, 10154 Torino, Italy. ${ }^{3}$ Istituto Superiore di Sanit, Dipartimento di Sanit Pubblica Veterinaria e Sicurezza Alimentare, Viale Regina Elena, 299, 00161 Roma, Italy. ${ }^{4}$ Dipartimento di Agraria, Universit degli Studi di Napoli Federico II , Via Universit 100, 80055 Portici, Italy.

Received: 12 March 2014 Accepted: 27 November 2014

Published online: 14 December 2014

\section{References}

1. Coppola S, Parente E, Dumontet S, La Peccerella A: The microflora of natural whey cultures utilized as starters in the manufacture of Mozzarella cheese from water-buffalo milk. Lait 1988, 68:295 310.

2. Adams LG, Templeton JW: Genetic resistance to bacterial diseases of animals. Rev Sci Tech 1998, 17:200 219.

3. Bishop SC, MacKenzie KM: Genetic management strategies for controlling infectious diseases in livestock populations. Genet Sel Evol 2003, 35(Suppl 1):S3 S17.

4. Capparelli R, Alfano F, Amoroso MG, Borriello G, Fenizia D, Bianco A, Roperto S, Roperto F, lannelli D: Protective effect of the Nramp1 BB genotype against Brucella abortus in the water buffalo (Bubalus bubalis). Infect Immun 2007, 75:988 996.

5. Trinchieri $\mathrm{G}$, Sher $\mathrm{A}$ : Cooperation of Toll-like receptor signals in innate immune defence. Nat Rev Immunol 2007, 7:179 190

6. Akira S, Takeda K, Kaisho T: Toll-like receptors: critical proteins linking innate and acquired immunity. Nat Immunol 2001, 2:675 680.

7. Takeda K, Akira S: TLR signaling pathways. Semin Immunol 2004, 16:3 9

8. Takeuchi O, Akira S: TOLL-like receptors; their physiological role and signal transduction system. Int Immunopharmacol 2001, 1:625 635.

9. Koets A, Santema W, Mertens $H$, Oostenrijk D, Keestra M, Overdijk M, Labouriau R, Franken P, Frijters A, Nielen M, Rutten V: Susceptibility to paratuberculosis infection in cattle is associated with single nucleotide polymorphisms in Toll-like receptor 2 which modulate immune responses against Mycobacterium avium subspecies paratuberculosis. Prev Vet Med 2010, 93:305 315

10. Lorenz E, Mira JP, Cornish KL, Arbour NC, Schwartz DA: A novel polymorphism in the toll-like receptor 2 gene and its potential association with staphylococcal infection. Infect Immun 2000, 68:6398 6401

11. Mucha R, Bhide MR, Chakurkar EB, Novak M, Mikula I Sr: Toll-like receptors TLR1, TLR2 and TLR4 gene mutations and natural resistance to Mycobacterium avium subsp. paratuberculosis infection in cattle. Vet Immunol Immunopathol 2009, 128:381 388.

12. Pinedo PJ, Buergelt CD, Donovan GA, Melendez P, Morel L, Wu R, Langaee TY, Rae DO: Candidate gene polymorphisms (BoIFNG, TLR4, SLC11A1) as 
risk factors for paratuberculosis infection in cattle. Prev Vet Med 2009, 91:189 196.

13. Smirnova I, Poltorak A, Chan EK, McBride C, Beutler B: Phylogenetic variation and polymorphism at the toll-like receptor 4 locus (TLR4). Genome Biol 2000, 1:1.

14. Sun L, Song $Y$, Riaz H, Yang H, Hua G, Guo A, Yang L: Polymorphisms in toll-like receptor 1 and 9 genes and their association with tuberculosis susceptibility in Chinese Holstein cattle. Vet Immunol Immunopathol 2012, 147:195 201.

15. Tabel Y, Berdeli A, Mir S: Association of TLR2 gene Arg753Gln polymorphism with urinary tract infection in children. Int J Immunogenet 2007, 34:399 405.

16. Wei T, Gong J, Jamitzky F, Heckl WM, Stark RW, Rssle SC: Homology modeling of human Toll-like receptors TLR7, 8, and 9 ligand-binding domains. Protein Sci 2009, 18:1684 1691.

17. Medzhitov R: Toll-like receptors and innate immunity. Nat Rev Immuno 2001, 1:135 145

18. Amaral ME, Grant JR, Riggs PK, Stafuzza NB, Filho EA, Goldammer T, Weikard R, Brunner RM, Kochan KJ, Greco AJ, Jeong J, Cai Z, Lin G, Prasad A, Kumar S, Saradhi GP, Mathew B, Kumar MA, Miziara MN, Mariani P Caetano AR, Galvo SR, Tantia MS, Vijh RK, Mishra B, Kumar ST, Pelai VA, Santana AM, Fornitano LC, Jones BC, et al: A first generation whole genome $\mathrm{RH}$ map of the river buffalo with comparison to domestic cattle. BMC Genomics 2008, 9:631.

19. Mitra M, Taraphder S, Sonawane GS, Verma A: Nucleotide sequencing and SNP detection of Toll-like receptor-4 gene in Murah Buffalo (Bubalus bubalis). Int ScholRes Net 2012, 7:659513. Art. ID.

20. Poltorak A, He X, Smirnova I, Liu MY, Huffel CV, Du X, Birdwell D, Alejos E, Silva M, Galanos C, Freudenberg M, Ricciardi-Castagnoli P, Layton B, Beutler B: Defective LPS signaling in $\mathrm{C} 3 \mathrm{H} / \mathrm{HeJ}$ and $\mathrm{C} 57 \mathrm{BL} / 10 \mathrm{ScCr}$ mice: mutations in TLR4 gene. Science 1998, 282:2085 2088.

21. Quesniaux V, Fremond C, Jacobs M, Parida S, Nicolle D, Yeremeev V, Bihl F, Erard F, Botha T, Drennan M, Soler MN, Le Bert M, Schnyder B, Ryffel B: Toll-like receptor pathways in the immune responses to mycobacteria. Microbes Infect 2004, 6:946 959.

22. Griebel PJ, Brownlie R, Manuja A, Nichani A, Mookherjee N, Popowych Y, Mutwiri G, Hecker R, Babiuk LA: Bovine toll-like receptor 9: A comparative analysis of molecular structure, function and expression. Vet Immunol Immunopathol 2005, 108:11 16

23. Marchler-Bauer A, Lu S, Anderson JB, Chitsaz F, Derbyshire MK, DeWeese-Scott C, Fong JH, Geer LY, Geer RC, Gonzales NR, Gwadz M, Hurwitz DI, Jackson JD, Ke Z, Lanczycki CJ, Lu F, Marchler GH, Mullokandov M, Omelchenko MV, Robertson CL, Song JS, Thanki N, Yamashita RA, Zhang D, Zhang N, Zheng C, Bryant SH: CDD: specific functional annotation with the Conserved Domain Database. Nucleic Acids Res 2009, 37:205 210.

24. Marchler-Bauer A, Lu S, Anderson JB, Chitsaz F, Derbyshire MK, DeWeese-Scott C, Fong JH, Geer LY, Geer RC, Gonzales NR, Gwadz M, Hurwitz DI, Jackson JD, Ke Z, Lanczycki CJ, Lu F, Marchler GH, Mullokandov M, Omelchenko MV, Robertson CL, Song JS, Thanki N, Yamashita RA, Zhang D, Zhang N, Zheng C, Bryant SH, CDD: A Conserved domain database for the functional annotation of proteins. Nucleic Acids Res 2011, 39:225 229.

25. Acutis PL, Martucci F, D Angelo A, Peletto S, Colussi S, Maurella C, Porcario C, Iulini B, Mazza M, Dell Atti L, Zuccon F, Corona C, Martinelli N, Casalone C, Caramelli M, Lombardi G: Resistance to classical scrapie in experimentally challenged goats carrying mutation K222 of the prion protein gene. Vet Res 2012, 43:8.

26. Goldmann W, Hunter N, Smith G, Foster J, Hope J: PrP genotype and agent effects in scrapie: change in allelic interaction with different isolates of agent in sheep, a natural host of scrapie. J Gen Virol 1994 75:989 995

27. Novk K: Functional polymorphisms in Toll-like receptor genes for innate immunity in farm animals. Vet Immunol Immunopathol 2014, 157:1 11

28. Werling D, Piercy J, Coffey TJ: Expression of TOLL-like receptors (TLR) by bovine antigen-presenting cells-potential role in pathogen discrimination? Vet Immunol Immunopathol 2006, 112:2 11.

29. White SN, Taylor KH, Abbey CA, Gill CA, Womack JE: Haplotype variation in bovine Toll-like receptor 4 and computational prediction of a positively selected ligand-binding domain. Proc Natl Acad Sci U S A 2003, 100:10364 10369

30. Cargill EJ, Womack JE: Detection of polymorphisms in bovine toll-like receptors 3, 7, 8, and 9. Genomics 2007, 89:745 755
31. Torres-Garca D, Cruz-Lagunas A, Garca -Sancho Figueroa MC, Fernndez-Plata R, Baez-Saldaa R, Mendoza-Milla C, Barquera R, Carrera-Eusebio A, Ramrez-Bravo S, Campos L, Angeles J, Vargas-Alaren G, Granados J, Gopal R, Khader SA, Yunis EJ, Zuiga J: Variants in toll-like receptor 9 gene influence susceptibility to tuberculosis in a Mexican population. J Trans/ Med 2013, 11:220

32. Chamary JV, Hurst LD: The price of silent mutations. Sci Am 2009, 300:46 53

33. Sauna ZE, Kimchi-Sarfaty C, Ambudkar SV, Gottesman MM: The sounds of silence: synonymous mutations affect function. Pharmacogenomics 2007, 8:527 532.

34. Kobayashi K, Yuliwulandari R, Yanai H, Naka I, Lien LT, Hang NTL, Hijikata M, Keicho N, Tokunaga K: Association of TLR polymorphisms with development of tuberculosis in Indonesian females. Tissue Antigens 2012, 79:190 197.

35. Pagani F, Buratti E, Stuani C, Baralle FE: Missense, nonsense, and neutral mutations define juxtaposed regulatory elements of splicing in cystic fibrosis transmembrane regulator exon 9. J Biol Chem 2003, 278:26580 26588.

36. Pagani F, Raponi M, Baralle FE: Synonymous mutations in CFTR exon 12 affect splicing and are not neutral in evolution. Proc Natl Acad Sci U S A 2005, 102:6368 6372.

37. Capon F, Trembath RC, Barker JN: An update on the genetics of psoriasis. Dermatol Clin 2004, 22:339 347

38. OIE: Bovine tuberculosis. In Manual of Diagnostic Tests and Vaccines for Terrestrial Animals. 2013. Chapter 2.4.7

39. Hall TA: BioEdit: a user-friendly biological sequence alignment editor and analysis program for Windows 95/98/NT. Nucleis Acids Symposium Series 1999, 41:95 98

40. Gao X, Starmer J, Martin ER: A multiple testing correction method for genetic association studies using correlated single nucleotide polymorphisms. Genet Epidemiol 2008, 32:361 369.

41. Nyholt DR: A simple correction for multiple testing for single-nucleotide polymorphisms in linkage disequilibrium with each other. Am J Hum Genet 2004, 74:765 769 .

42. Stephens M, Smith NJ, Donnelly P: A new statistical method for haplotype reconstruction from population data. Am J Hum Genet 2001, 68:978 989.

doi:10.1186/s12863-014-0139-y

Cite this article as: Alfano et al:: Identification of single nucleotide polymorphisms in Toll-like receptor candidate genes associated with tuberculosis infection in water buffalo (Bubalus bubalis). BMC Genetics 2014 15:139.

\section{Submit your next manuscript to BioMed Central and take full advantage of:}

$\otimes$ Convenient online submission

$\otimes$ Thorough peer review

$\otimes$ No space constraints or color $₫$ gure charges

$\otimes$ Immediate publication on acceptance

\Inclusion in PubMed, CAS, Scopus and Google Scholar

$\otimes$ Research which is freely available for redistribution 